\title{
Favourable effect of Eugenol on liver histology in acute cholestasis in rats after bile duct ligation
}

\author{
Sarikaya $\mathrm{M}^{1}$, Filik L ${ }^{1}$, Ergul $\mathrm{B}^{1}$, Dogan $\mathrm{Z}^{1}$, Alparslan Gonultas $\mathrm{M}^{2}$, Hucumenoglu $\mathrm{S}^{2}$, \\ Can $\mathrm{M}^{3}$, Duymus $\mathrm{ME}^{4}$
}

Ankara Education and Research Hospital, Gastroenterology Clinic, Ankara, Turkey. drmuratsarikaya@gmail.com

\begin{abstract}
Background: Eugenol an essential oil found in clove was previously shown to have some anti-inflammatory properties. It also was shown to be linked to hepatoprotective effect. In this regard, we aimed to reveal the effect of eugenol on cholestatic liver disease.

Method: Cholestatic liver disease model was established in 20 rats via bile duct ligation. Eugenol was administered and cytokine levels and liver histology after sacrifice were evaluated.

Results: Biliary ductular proliferation and neutropil infiltration were lower in eugenol-administered rats.

Conclusion: Eugenol has a promising effect on liver histology in cholestatic liver disease (Tab. 1, Fig. 2, Ref. 16).

Text in PDF www.elis.sk.

Key words: biliary ductular proliferation, cholestatic liver disease, bile duct ligation, liver histology, acute cholestasis.
\end{abstract}

Eugenol (4-allyl-2-methoxyphenol) is the main component in the essential oil of clove (Syzygium aromaticum) and is also an important component of many aromatic plants including cinnamon and nutmeg. Eugenol has many biological and therapeutic properties including antioxidant, analgesic, neuroprotective and anti-inflammatory actions (1-3). Bis-eugenol consists of oxidated eugenol which has a greater antioxidant power than eugenol. Bis-eugenol activity inhibits lipopolysaccharide (LPS)-stimulated nuclear factor kappa- $\beta(\mathrm{NF}-\mathrm{K} \beta)$. Thereby, compounds that are related to eugenol may also have the anti-inflammatory effect (4).

Cholestasis is defined as an excessive accumulation of bile acids and seen as a flaw in the process of bile acid transport and bile formation $(5,6)$. Unfortunately the therapeutic options of dealing with this syndrome are limited, partially because the actual structure causing cholestatic liver injury has not been understood yet. Nevertheless, some key factors have been observed in late studies, such as cell death owing to necrosis or apoptosis, disorder in oxidative stress balance, inflammatory response, and release of profibrotic cytokines leading to activation of myofibroblasts modification in the extracellular matrix (ECM), and bile duct epithelial cell proliferation $(7,8)$. In general, these mechanisms lead to liver fibrosis.

Bile duct ligation (BDL) is a well-known experimental model used to create cholestatic liver disease (9). After BDL, intrahepatic

${ }^{1}$ Ankara Education and Research Hospital, Gastroenterology Clinic, Ankara, Turkey, ${ }^{2}$ Ankara Education and Research Hospital, Pathology Clinic, Ankara, Turkey, ${ }^{3}$ Bulent Ecevik University Medical School, Medical Biochemistry, Ankara, Turkey, and ${ }^{4}$ Ankara Education and Research Hospital, General Surgery Clinic, Ankara, Turkey

Address for correspondence: M. Sarikaya, MD, Ankara Education and Research Hospital, Gastroenterology Clinic, Ulucanlar, Altindag, Ankara, 06600, Turkey.

Phone: +90.505 .7668875 , Fax: +90.312 .3633396$ biliary epithelial cell proliferation, myofibroblastic differentiation of portal fibroblasts around proliferating biliary epithelial cells, and extracellular matrix deposition by these myofibroblasts are observed (10). The initial phases are characterized by acute cholestasis in which inflammation undertakes an important task. Apparently, inflammation is not the first factor and also appears in consequence of oxidative stress and bile acids accumulation. In our study, we aimed to reveal the effect of Eugenol on liver histology in BDL-induced cholestasis.

\section{Materials and methods}

\section{Experimental design}

In this study, 20 male Wistar albino rats, weighing about 200-250 g were used. Wistar albino rats were supplied from Ankara Education and Research Hospital of Experimental Research Laboratory (Ankara, Turkey). They were maintained in rat cages in an animal room on a 12 -hour light/ dark cycle at $21-22^{\circ} \mathrm{C}$. Rats were allowed ad libitum access to food and water. The structure of this study and animal experimental procedures were approved by the Ethical Committee of Ankara Education and Research Hospital and conducted in compliance with the rules of international Guiding Principles for Biomedical Research Involving Animals of the Council for International Organizations of Medical Sciences (CIOMS).

Wistar albino rats were divided into 4 groups $(n=5)$ as follows:

Group 1 (Control; $n=5$ ) just bile duct was cut out from the surrounding tissue (sham-operated).

Group 2 (BDL; $\mathrm{n}=5$ ) underwent only BDL.

Group 3 (Eugenol; $\mathrm{n}=5$ ) sham-operated and given Eugenol, $5 \mathrm{mg} / \mathrm{kg} /$ day into stomach by a soft $6 \mathrm{~F}$ pediatric catheter starting 24 hours after BDL for 7 days. 
Group $4(\mathrm{BDL}+$ Eugenol; $\mathrm{n}=5$ ) underwent BDL and were given Eugenol, $5 \mathrm{mg} / \mathrm{kg} /$ day into stomach by a soft $6 \mathrm{~F}$ pediatric catheter starting 24 hours after BDL for 7 days.

BDL was carried out as follows in brief:

Each rat was anesthetized with Ketamine and Xylazine cocktail. The abdomen was cleaned with $10 \%$ povidone iodine and after that a midline laparotomy was performed. The bile duct was isolated and ligated. Eugenol was obtained from a chemical company (ABCS Inc. Co.).

After 7 days from the beginning of the study, all animals were sacrificed by decapitation. Their liver and common bile duct tissues were collected.

\section{Histological examination}

Samples were preserved in $10 \%$ formalin for histological examination. Formalin-fixed liver tissue samples were embedded in paraffin and sections were stained with hematoxylin-eosin and Masson's trichrome methods. The images were taken and samples were examined by an impartial observer blinded to the experimental protocol. The degree of cholestasis was determined by guides of Christoffersen and Polsen (11). The criteria used to evaluate cholestasis included edema, proliferation of ductular structures, and neutrophil infiltration.

\section{Biochemical analysis}

The liver samples were homogenized with Ultra Turrax homogenizer (T25-B, IKA, Labortechnic, Germany) in Tris / Tween buffer. The homogenate was then centrifuged at $8000 \mathrm{~g}$ at 4 centigrades. The supernatant fluid was taken and TGF- $\beta 1$, TNF- $\alpha$ and IL- $1 \beta$ protein concentrations were measured with Lowry method (12). The level of cytokines was assessed as $\mathrm{pg} / \mathrm{mL}$. Tissue TGF$\beta 1$ levels were measured by competitive enzyme immunoassay using ELISA kits (eBioscience, Vienna, Austria) while following the manufacturer's protocol. The intra- and inter-assay CV were less than $6.9 \%$ and $12 \%$ for TGF- $\beta 1$. Tissue TNF- $\alpha$ levels were measured by competitive enzyme immunoassay using ELISA kits (eBioscience, Vienna, Austria) while following the manufacturer's protocol. The intra- and inter-assay CV were less than $5.0 \%$ and $10 \%$ for TNF- $\alpha$. Tissue IL- $1 \beta$ levels were measured by competitive enzyme immunoassay using ELISA kits (eBioscience, Vienna, Austria) while following the manufacturer's protocol. The intra-and inter-assay CV were less than $10 \%$ and $10 \%$ for IL- $1 \beta$.

\section{Statistical analysis}

Statistical analyses were performed by SPSS statistical software (version 15.0 for Windows; SPSS Inc, Chicago, IL, U.S.A). Statistical analyses for levels of TNF- $\alpha$, IL- $1 \beta$ and TGF- $\beta$ were performed by using one-way ANOVA followed by Tukey's multiple comparison test. $\mathrm{P}$ values less than 0.05 were considered statistically significant.

\section{Results}

The distinctive triad (edema, ductular proliferation and neutrophil reaction) of acute cholestasis and fibrosis was seen in group
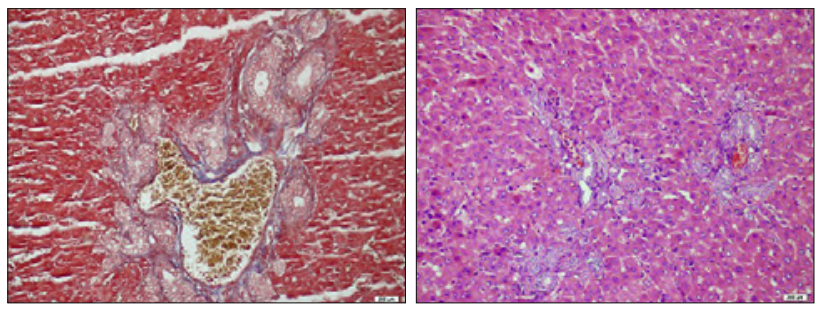

Fig. 1. Hematoxylin-eosin and Masson's trichrome stain showing acute cholestasis and fibrosis seen in BDL rats.
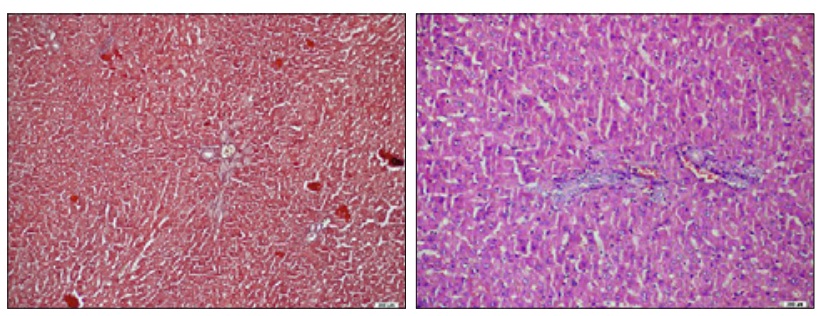

Fig. 2. Hematoxylin-eosin and Masson's trichrome stain showing significant histological alleviation in eugenol-administered BDL rats.

2 (rats with BDL) (Fig. 1). Bile pigment was typically in centrilobular regions. We observed a significant histological alleviation in eugenol-administered BDL rats (group 4) (Fig. 2). Ductular proliferation and neutrophil infiltration were comparably smaller than in group 2. Eugenol did not yield pathological changes in group 3.

Anti-inflammatory effects of eugenol on BDL-induced cholestasis in rats were assessed by IL-1 $\beta$, TNF- $\alpha$ and TGF $\beta$ levels. Although the histological benefit was observed in all eugenoladministered rats, the levels of IL- $1 \beta$, TNF- $\alpha$ and TGF $\beta$ levels did not show any concordant changes $(p>0.05)$.

\section{Discussion}

Eugenol as a common dietary component has been under investigation for decades. Its hepatoprotective role was demonstrated in several studies. Nagababu et al demonstrated the protective role of eugenol in CCl4 administered rats (13). They underlined that eugenol was effective if given concurrently or soon after CCl4. They also showed the antioxidative effects of eugenol in another rat model study (14).

Liver is a unique organ in the body that has a major role in detoxification of toxicants (15). During the detoxification process inevitable hepatotoxicity develops. Liver damage due to cholestasis is one of the common clinical problems due to drugs, alcohol or biliary obsructions. Accordingly, some of the recent studies have revealed the possible effect protective and therapeutic dietary or botanical remedies to handle these common problems. In our study we observed a significant amelioration of biliary inflammation in rats after BDL. This is an acute inflammation model because it lasts only seven days till sacrifice. Histological examination disclosed a comparably smaller biliary inflammation in eugenol-administered rats with BDL. Nevertheless, we did not detect concordant cytokine levels (IL-1 $\beta, \mathrm{TNF} \alpha$, TGF) in rats $(\mathrm{p}>0.05)$. Eugenol has previously demonstrated to have anti-inflammatory effect through cy- 
tokines (16). Histological alleviation in our study can be attributed to another effect that is different from cytokines such as IL-1 $\beta$, $\mathrm{TNF} \alpha$, TGF levels. It remains to be elucidated with new studies.

On the other hand there are some data that show the possible toxicity by eugenol, just like by other essential oils. Eugenol was claimed to have neurotoxicitiy or carcinogenicity in high doses. In our study, we did not observe hepatotoxicity linked to eugenol at dosage of $5 \mathrm{mg} / \mathrm{kg} /$ day. That is why pros and cons of eugenol use in clinical studies should be compared before the clinical studies proceed.

In conclusion, eugenol seems to have a favorable effect on liver histology when used against cholestasis. In this regard, new studies are necessary to establish an exact role and mechanisms of eugenol in hepatotoxicity.

\section{References}

1. Park SH, Sim YB, Lee JK, Kim SM, Kang YJ, Jung JS, Suh HW. The analgesic effects and mechanisms of orally administered eugenol. Arch Pharm Res 2011; 34: 501-507.

2. Yogalakshmi B, Viswanathan P, Anuradha CV. Investigation of antioxidant, antiinflammatory and DNA-protective properties of eugenol in thioacetamide-induced liver injury in rats. Toxicology 2010; 268: 204-212.

3. Grespan R, Paludo M, Lemos Hde P, Barbosa CP, Bersani-Amado CA, Dalalio MM, Cuman RK. Anti-arthritic effect of eugenol on collagen-induced arthritis experimental model. Biol Pharm Bull 2012; 35 (10): 1818-1820.

4. Murakami Y, Shoji M, Hanazawa S, Tanaka S, Fujisawa S. Preventive effect of bis-eugenol, a eugenol ortho dimer, on lipopolysaccharidestimulated nuclear factor kappa B activation and inflammatory cytokine expression in macrophages. Biochem Pharmacol 2003; 66 (6): 1061-1066.

5. Tomur A, Kanter M, Gurel A, Erboga M. The efficiency of CAPE on retardation of hepatic fibrosis in biliary obstructedrats. J Mol Histol 2011; 42: 451-458.
6. Olteanu D, Nagy A, Dudea M et al. Hepatic and systemic effects of rosuvastatin on an experimental model of bile duct ligation in rats. J Physiol Pharmacol 2012; 63: 483-496.

7. Forbes SJ, Parola M. Liver fibrogenic cells. Best Pract Res Clin Gastroenterol 2011; 25: 207-217.

8. Olteanu D, Filip A, Mureşan A et al. The effects of chitosan and low dose dexamethasone on extrahepatic cholestasis after bile duct ligation in Wistar rats. Acta Physiol Hung 2012; 99: 61-73.

9. Tuchweber B, Desmoulière A, Bochaton-Piallat ML, Rubbia-Brandt L, Gabbiani G. Proliferation and phenotypic modulation of portal fibroblasts in the early stages of cholestatic fibrosis in the rat. Lab Invest 1996; 74: 265-278.

10. Desmoulière A, Darby I, Costa AM, Raccurt M, Tuchweber B, Sommer P, Gabbiani G. Extracellular matrix deposition, lysyl oxidase expression, and myofibroblastic differentiation during the initial stages of cholestatic fibrosis in the rat. Lab Invest 1997; 76: 765-778.

11. Christoffersen P, Poulsen H. Histological changes in human liver biopsies following extrahepatic biliary obstruction. Acta Pathol Microbiol Scand 1970; 212: 150-157.

12. Lowry OH, Rosebrough NJ, Farr A, Randall RJ. Protein measurement with the folin phenol reagent. J Biol Chem 1951; 193: 265-275.

13. Nagababu E, Sesikeran B, Lakshmaiah $\mathbf{N}$. The protective effects of eugenol on carbon tetrachloride induced hepatotoxicity in rats. Free Radic Res 1995; 23: 617-627.

14. Nagababu E, Rifkind JM, Boindala S, Nakka L. Assessment of antioxidant activity of eugenol in vitro and in vivo. Methods Mol Biol 2010; 610: 165-180.

15. Mori K, Matsumoto K, Gans H. On the in vivo clearance and detoxification of endotoxin by lung and liver. Ann Surg 1973; 177: 159-163.

16. Liu Y, Song M, Che TM, Bravo D, Pettigrew JE. Antiinflammatory effects of several plant extracts on porcine alveolar macrophages in vitro. J Anim Sci 2012; 90: 2774-2783. 